\title{
Fault Analysis of Distribution Network with Flexible Ring Network Control Device
}

\author{
Kuo Tan ${ }^{1, a}$, Chenghong Tang ${ }^{1, b}$, Jingtao Zhao ${ }^{1, c}$, Shu Zheng ${ }^{1, d}$ \\ 1.NARI Group Corporation, Nanjing 210003, China \\ atankuo@sgepri.sgcc.com.cn, tangchenghong@sgepri.sgcc.com.cn, \\ czhaojingtao@sgepri.sgcc.com.cn, 'zhengshu@sgepri.sgcc.com.cn
}

\begin{abstract}
Keywords: AC/DC hybrid distribution network, Flexible Ring Network Control Device, Distribution network protection, fault analysis

Abstract. With the rapid development of the power electronic technology and control technology, the use of the IGBT, IGCT full controlled devices consisting of a voltage source converter (voltage source converter, VSC) in the DC transmission system has been widely used. However, rapid response of power electronic devices and control systems, protective properties of the AC system impact. Study of DC system in DC interconnected system on the protection of AC system effects have important theoretical significance and practical value. Based on the output characteristics in a comprehensive grasp of the AC distribution network protection, feeder automation and flexible loop network control device fault, in-depth analysis of its access to distribution network in different position, different types of fault when fault characteristics and the traditional AC power distribution of the difference between, on the basis of study the applicability of traditional AC distribution line protection strategy and improvement strategy.
\end{abstract}

\section{Introduction}

With the rapid development of the power electronic technology and control technology, the IGBT, IGCT, full control type components of voltage source converter is widely used in DC power transmission system, and successfully applied in many fields, due to power electronic devices and the control system of the fast response should be, relay protection device of the AC system impact. Power system relay protection device is an important part of the power system. It plays an important role in ensuring the safe operation of the system when the system is in trouble and is not in normal operation. Therefore, it is of great theoretical significance and practical value to study the influence of DC system on AC relay protection device in AC / DC interconnected system. It is necessary to fully grasp the flexible loop network control device fault output characteristics based on the in-depth analysis of its access to distribution network in different position, different types of faults, the difference between fault characteristics and the traditional AC power distribution network, based on research on the applicability of traditional AC distribution line protection strategy and improvement strategy.

The different control strategies of different topologies of AC / DC hybrid distribution network under various fault conditions are analyzed by literature [1-2]. The literature [3] in the AC side voltage occurs asymmetric fault, according to the characteristics of zero sequence current path failures in the system and put forward the fault system of positive, negative and zero sequence controller and the system active power control strategy. The literature [4] for converter station of the lock up period power module capacitor voltage gradually diverge and eventually lead to AC circuit breaker tripping problem, put forward the fault through the period, the converter is in a controllable state, to avoid the divergence of capacitor voltage, without the need to shut off the cross connect DC system, can immediately resume normal operation of control and protection strategy in the after fault clearing. The failure mechanism and corresponding fault characteristics of AC / DC hybrid system are analyzed by literature [5-6]. In 500kV treasure and expensive - Guang II HVDC project as a model, on the basis of a large number of real-time digital simulation system (RTDS) test, from the perspective of application of relay protection of first systematically analyzes the AC / DC hybrid AC system fault feature. For typical AC grounding mode, the establishment of a unipolar grounding fault transient 
analysis model, analysis the influence of grounding device parameters on the failure characteristic, for the problem of converter fault recovery, further analyzes the, under the bridge arm capacitor voltage rebalancing mechanism. The literature [7] analysis of DC line fault mechanism, fault analysis of the output characteristics of the system. The results show that the bipolar short-circuit when the sub module capacitor discharge is the cause of the impact of transient current, coupling transformer valve side fed and is stable fault currents, whereas the monopolar grounding fault will because the coupling effect of transformer which is transferred to the non fault side, thus bring the negative influence to the system. The literature [8] respectively to exchange system side, valve side and DC grounding fault as an example. Analysis that at the time of the failure, working mechanism, modulation strategy and topology differences lead to system presents and traditional DC voltage source converter type gravity transmission small fault characteristics, and based on this proposed coping strategies.

\section{Current status of protection and feeder automation technology in AC distribution network}

\section{Current protection based on circuit breaker}

The traditional three-step current protection, namely the instantaneous speed of break protection, time limit quick break, timing and limiting current protection, is in response to the current increase in and action of protection, the difference between them mainly lies in according to the different setting principle to select the starting current. Quick break is to avoid a point the maximum short-circuit current setting, time limit quick break is according to escape across the front of adjacent elements current quick break protection action current setting, and the over current protection is to avoid the maximum load current setting. The advantages of staged current protection are simple and reliable, so it has been widely used in the $35 \mathrm{kV}$. The disadvantage is that it is directly affected by the connection of the power grid and the change of the power system operation mode, which makes it often can not meet the requirements of the sensitivity coefficient or the scope of protection.

\section{Feeder automation}

Feeder automation is an integrated system which can monitor, adjust and control the equipment on distribution line. The main significance lies in improving the reliability of power supply. When the distribution network has a fault or abnormal operation, quickly find out the fault section, quickly isolate the fault section, in time to restore the power supply to the non fault area users, shorten the outage time, reduce the power outage area. According to the different ways of fault treatment, there are two main modes of feeder automation, that is, feeder automation based on local automatic switching equipment and feeder automation based on centralized monitoring.

Based on in situ automatic switch equipment of feeder automation of this mode of feeder automation, the main equipment is recloser and sectionalizer, short-circuit current by the recloser resection, sectionalizer only closing short-circuit current, do not cut off the short circuit current. Now in an attempt to a system, for example, B for reclosers, $\mathrm{s}$ for flow pulse counting type sectionalizer, under normal circumstances B0 disconnect in open-loop operation. In this model, each switch, pre-set a good coincidence times, when the switch contact number reaches the set value and switch is in the switch state, locking automatic closing function, fault isolation. For the coincidence device, the interval time T1 is also provided, which is the time interval of the closing operation. Sectionalizer close operation depends on the line voltage, switching power loss is the brake, after the call is closing.

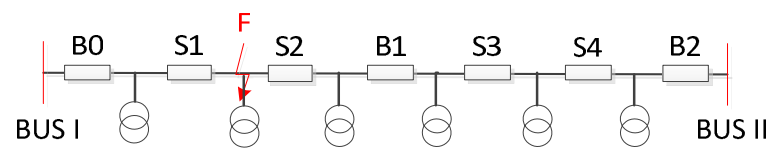

Fig1 Feeder automation based on coincidence device and segment

For the distribution network as shown in fig 1, the coincidence times of B2 and B1 are set to 3 times, $\mathrm{B} 0$ is set to 2 times, $\mathrm{S} 1$ and $\mathrm{S} 3$ are set to 2 times, $\mathrm{S} 2$ and $\mathrm{S} 4$ are 1 times. When a short-circuit occurs at $\mathrm{F} 1, \mathrm{~B} 1$ before the gate fault makes $\mathrm{S} 1$ and $\mathrm{S} 2$ have lost pressure gate, while B1 start time. Time to B1, 
T1 first coincidence, S1 was also the pressure after the coincidence, recorded 1 times. Because it is a permanent fault, so the line second times the fault current. B1 and S1 for the second sub closing operation, recorded 2 times. For the third time, the fault current, B1 and S1 are divided into third sub gates. For S1, because it is in the switch state and it coincides with the number has reached set value 2, with atresia, so S1 closing and locking, which will isolate the fault. B1 again coincide, restore the S1 - B1 section of the line power supply. After a period of delay, the switch B0 coincidence, to restore the B0 - S2 section of the line power supply. The advantages of the model are simple structure, low construction cost, and the improvement of the power supply can be improved. Depending on the nature of a certain role, compared with the traditional current protection has a larger advantage, is a simple economic program. The disadvantage is that when the fault is isolated, it needs to be repeated several times, the impact on the equipment is large, and the power supply time is long.

The characteristics of feeder automation based on centralized control is to make full use of the communication network, the main equipment has feeder terminal unit FTU, circuit breaker, load switch and background control master station. When a fault happens in the power grid, FTU to control station transmits the fault and fault information, control station based on FTU information and topological structure of distribution network, through analysis and calculation for fault location, and determine optimal fault restoration scheme, a remote control command corresponding to the switching action, implementing fault isolation and restoration of power supply of non fault zone. As shown in fig2, for the circuit breaker B and the load switch $\mathrm{S}$, the circuit breakers and switches are installed with FTU, the normal operation of S3 off, in the open loop operation. The basic principle of this model is: when the switch S1 and switch S2 fault F1 (non - Single - phase grounding), the circuit breaker B1 action, the circuit breaker will be removed. Installed in the S1 FTU to detect a fault current, and installed in the switch S2 FTU no fault current flows. At this time automation system will confirm the fault occurred between the S1 and S2, remote control tripping S1 and S2, the realization of fault isolation and remote on line outlet circuit breaker B1, the most close contact B0 switch, complete to the non fault area to restore power.

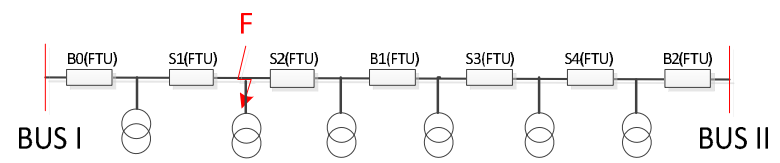

Fig2 Feeder automation based on FTU

The scheme is the mainstream of the current feeder automation program, compared with the first two ways, it can effectively improve the reliability of the power supply from the aspects of fault removal, fault isolation and restoration of power supply. But this protection is essentially in the automatic device without selective action after the restoration of power supply, so to a certain extent, reduce the reliability of the power supply, and a strong dependence on the communication network. When the communication system or the control center failure, will cause the entire system to paralysis, loss of fault isolation, restore the function of power supply.

The realization technology of intelligent distributed FA includes fault location, isolation technology and power recovery technology of non fault section. There is through the establishment of the terminal to the node is associated with a list and analysis to the node list, the establishment of a to the associated node data sharing, and parsing a receive module receives real-time node correlation information through the goose, failure to achieve the fast fault diagnosis and isolation.

\section{Fault analysis of distribution network with flexible ring network control device}

\section{Characteristic analysis of control device of flexible ring network with different topology}

Two level VSC converter control is simple, mature technology, is the ABB company's VSC-HVDC transmission system and STATCOM project is one of the main topology. Two level VSC converter has broad application prospects in the field of distributed power distribution network and low voltage microgrid. Three level VSC converter control is simple, technology is mature, also belong to the 
current VSC-HVDC company's ABB transmission system and STATCOM project is one of the main uses of the topology. Compared with the conventional two level converter, using the same switching device, the three level converter can improve the voltage level of the AC output. On the other hand, in the harmonic characteristics, using the same switching frequency, the harmonic frequency of the AC output side will be doubled. But in the application of the $10 \mathrm{kV} \mathrm{AC} \mathrm{/} \mathrm{DC} \mathrm{hybrid} \mathrm{power} \mathrm{distribution}$ network, the flexible loop network control device still need to be directly connected in series, and the problem is completely the same as the two level converter. For the three level converter, the main harmonics are significantly reduced, but the filter is still necessary in the AC side. So in the application of flexible HVDC system, the three level NPC converter and two level converter are similar technology, which belong to the low level number converter combined with a series of switching devices. Restricted the withstand voltage level, the traditional three-phase two-level and three-level VSC using device series technology to achieve different voltage level of the DC output device is directly connected technology of IGBT consistency and equalizing technology put forward higher requirements, in China, there is no use direct series technology of flexible HVDC project application.

\section{Fault characteristics analysis of $10 \mathrm{kV}$ AC / DC hybrid power distribution network}

Fig 3 shows a schematic diagram of the $10 \mathrm{kV}$ flexible ring network control access AC distribution network, and the three terminal flexible DC device is used to realize the closed-loop operation of the single loop network and the interconnection between the adjacent link network. The fault characteristics of the AC system on one side of the flexible ring network control device are analyzed.

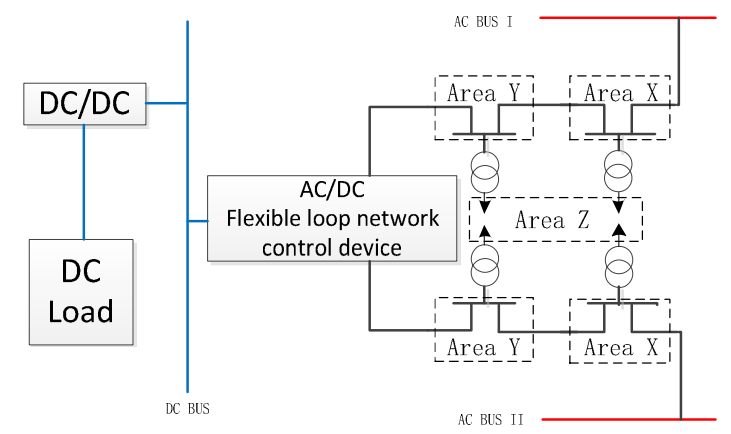

Fig3 Schematic diagram of 10kV flexible ring network control access distribution network As shown in Figure 3, flexible ring network control device on the side of the AC system, according to the fault characteristics of the $\mathrm{AC}$ system is divided into three parts: part of $\mathrm{X}$ system equivalent power and flexible ring network control device between except lead line of flexible ring network device line, y for flexible loop network control device of lead wire, $\mathrm{Z}$ part for other routes.

The traditional distribution network for a radial network with a single ended power supply, flexible access ring network control device, change multiterminal power supply network. Considering the flexible loop network control device not only can work as the rectifier and work in the inverter state, $\mathrm{x}$, y part contains the line power flow direction is no longer a single, and when the fault occurs in the communication system, flexible ring network control devices will provide some of the fault current. The traditional distribution network protection is the three stage current protection, which is not applicable to the $\mathrm{X}$ and $\mathrm{Y}$ parts of the flexible loop network control device. And for the part of the $\mathrm{Z}$ line, flexible ring network control device access will not change the direction of power flow, also taking into the flexible loop network control device not only can work as the rectifier and work in the inverter state, it is known the flexible loop network control device is connected to the can affect the $\mathrm{Z}$ line current protection scope of protection.

The low voltage ride through strategy of the flexible loop network control device is more complex than that of the distributed power supply, which makes the fault characteristics of the AC / DC hybrid power distribution network with the characteristics of the fast motion of the flexible loop network control device more complex. 


\section{Improvement strategy of the protection principle about $10 \mathrm{kV} \mathrm{AC} / \mathrm{DC}$ mixed distribution network}

As shown in Figure 4, the original protection principle and the applicability of the $10 \mathrm{kV}$ AC DC system are analyzed, and the improvement strategy is proposed.

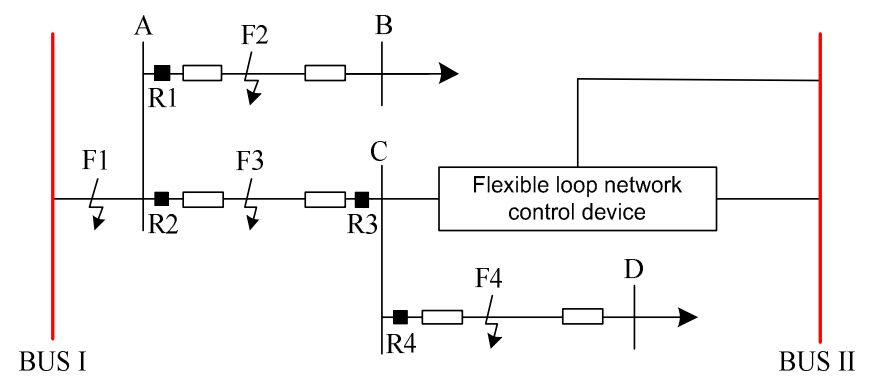

Fig 4 10kV Schematic diagram of AC / DC system

The Applicability analysis of traditional $10 \mathrm{kV}$ AC/DC system protection principle and direction element

1) Applicability analysis of three stage current protection

Three stage current protection for low voltage distribution network commonly used protection. When a short circuit fault occurs in the traditional AC power grid, the short circuit current is larger, so the three section current protection can act reliably. The applicability of the three section current protection in AC circuit of $10 \mathrm{kV}$ AC / DC system is investigated.

As shown in fig 4 when the line AC neutral point occurs BC short circuit fault, the protection of R2, R3 measured three-phase currents, respectively, the fault moment is $1 \mathrm{~s}$. Comparison can be found, flowing through the protection of B R2, C phase current significantly increased, about 20 times the normal operation, and flows through the protection of B R3, C phase current is not significantly increased (less than 2 times), resulting in current protection and rejection. This is due to the flexible ring network control device has limited the ability of the size of the output current and convection by R3 fault current with less, and line CD for passive branch, so through protection R3 B, C phase current is not increased significantly, due to protect $\mathrm{R} 2$ dorsal by traditional AC power to provide fault current, which flows through the protection R2 B, C phase current increases, traditional three-step current protection still apply.

When $\mathrm{BC}$ phase to phase short circuit fault occurs in the midpoint of the line $\mathrm{CD}$, due to protect the $\mathrm{R} 4$ dorsal by traditional $\mathrm{AC}$ power supply and a flexible ring network control device together to provide fault current, flows through the protection $\mathrm{R} 4 \mathrm{~B}, \mathrm{C}$ phase current increases, so the traditional current protection still apply.

In summary, the dorsal by flexible ring network control device to provide a separate fault current protection, traditional current protection does not apply; for dorsal by traditional AC power supply and a flexible ring network control device together to provide the protection for the fault current, and dorsal only by the traditional AC power to provide fault current protection, traditional current protection principle still applies.

2) Applicability analysis of Power directional element

For a flexible ring network control device, the $\mathrm{AC}$ and $\mathrm{DC}$ hybrid power distribution network is connected to the AC fault side converter, which is still in the four quadrant of the power. As shown in Figure 4-1, fault line BC, for example, assuming flexible loop network control devices still maintain the running state of the rectifier, power by side to AC DC transfer, is R3 power directional element for measuring to short-circuit power direction by the line flow to the bus, and the fault as a reverse fault. Therefore, the protection of the fault current is provided for the back side only by the flexible loop net control device, and the traditional power direction element is not applicable.

Improvement strategy of protection principle about $10 \mathrm{kV}$ AC/DC mixed distribution network Because of the flexible ring network control device taken to suppress negative sequence current control strategy, thus AC system asymmetric fault, flexible ring network control device output current does not contain negative sequence component, so negative sequence network does not contain a 
flexible loop network control device where the slip. So the negative sequence network is similar to the traditional communication system, and only the fault point has negative sequence voltage source. Therefore, the AC line can be considered to adopt the negative sequence overcurrent protection, and consider the negative sequence power direction element to identify the positive and negative direction faults. For the symmetrical fault of AC system, we can consider the method of controlling the delay of a phase filter data window in the three-phase current to obtain the negative sequence.

\section{Conclusions}

Because of the flexible ring network control device taken to suppress negative sequence current control strategy, thus AC system asymmetric fault, flexible ring network control device output current does not contain negative sequence component, so negative sequence network does not contain a flexible loop network control device where the slip. So the negative sequence network is similar to the traditional communication system, and only the fault point has negative sequence voltage source. Therefore, the AC line can be considered to adopt the negative sequence overcurrent protection, and consider the negative sequence power direction element to identify the positive and negative direction faults. For the symmetrical fault of $\mathrm{AC}$ system, we can consider the method of controlling the delay of a phase filter data window in the three-phase current to obtain the negative sequence.

\section{Acknowledgements}

This paper is founded by State 863 project that is key technology of AC/DC hybrid power distribution network under grant No.2015AA050102.

\section{References}

[1] Lian Chen, Hang Zhao, [J]. Journal of electric power science and technology, 2015(3):31-39. In Chinese.

[2] Chongbo Sun, Peng li, Chengshan Wang. [J]. Automation of electric power system, 2015(21):59-65. In Chinese.

[3] Yue Guo, Hongbin Zhang, Weihong Du. [J]. Electrical technique, 2015(2):49-52. In Chinese.

[4] Guomeng Sun, Pei Han, [J]. power construction, 2016(5) . In Chinese.

[5] Lin Cheng, Xu Wang, Junhui Huang. [J]. power construction, 2016(5). In Chinese.

[6] ChengFeng, Jianguo Chen, Yingshuang WU. [J]. Guizhou electric power technology, 2013(3):1-4. In Chinese.

[7] Zhixin Wang, Jie Wu, Lie Xu. [J]. Chinese Journal of Electrical Engineering,2016,01:40-46 . In Chinese.

[8] Xinming Fan, Lin Gaun, Chengjun Xia. [J]. Chinese Journal of Electrical Engineering, 2014, 34(28):4781-4790. In Chinese. 